\title{
CORRECTION
}

View Article Online

View Journal | View Issue

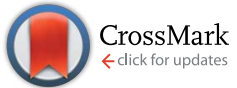

Cite this: J. Mater. Chem. A, 2016, 4 , 17875

DOI: $10.1039 / c 6 t a 90225 a$

www.rsc.org/MaterialsA

\section{Correction: Hydrogenated under-stoichiometric tungsten oxide anode interlayers for efficient and stable organic photovoltaics}

\author{
M. Vasilopoulou, ${ }^{* a}$ A. Soultati, ${ }^{a}$ D. G. Georgiadou, ${ }^{a}$ T. Stergiopoulos, ${ }^{a}$ L. C. Palilis, ${ }^{b}$ \\ S. Kennou, ${ }^{C}$ N. A. Stathopoulos, ${ }^{d}$ D. Davazoglou ${ }^{a}$ and P. Argitis ${ }^{a}$
}

Correction for 'Hydrogenated under-stoichiometric tungsten oxide anode interlayers for efficient and stable organic photovoltaics' by M. Vasilopoulou et al., J. Mater. Chem. A, 2014, 2, 1738-1749.

Some issues regarding Fig. 1 and 2 of the above manuscript are clarified as follows.

\section{Fig. 1}

The authors wish to acknowledge that, inadvertently, the binding energy in the horizontal axis of Fig. 1 is listed as a.u. instead of the appropriate units which is $\mathrm{eV}$.

The authors wish to also note that Fig. 1a-c showing the XPS data of the tungsten oxide films, present a small and rather broad feature at around $42 \mathrm{eV}$ which corresponds to $\mathrm{W} 5 \mathrm{p}_{3 / 2}$. This feature was fitted in Fig. 1a, although it is not very distinct due to the lower intensity of the signal, whereas it was not fitted in Fig. $1 \mathrm{~b}$ and $\mathrm{c}$ as any changes to the oxide stoichiometry were related only to the W4f XPS peaks.

\section{Fig. 2}

The caption of Fig. 2 should read:

Fig. 2 UPS photoemission spectra of the tungsten oxides prepared in this study: (a) the secondary-electron cut-off region, (b) full view of the valence band spectra and (c) the near $E_{\mathrm{F}}$ region.

The spectra shown in Fig. 2a are different measurements than those shown in Fig. 2b and $\mathrm{c}$ taken, however, on the same samples.

The use of a higher sensitivity UPS measurement in Fig. 2a was deemed necessary in order to alleviate, if possible, the intensity of the shoulder present just above the cut-off of the reduced film (Fig. 2b) and more reliably and accurately determine the films work function values (shown in Fig. 2a).

The Royal Society of Chemistry apologises for these errors and any consequent inconvenience to authors and readers.

\footnotetext{
"Institute of Advanced Materials, Physicochemical Processes, Nanotechnology and Microsystems (IAMPPNM), National Center for Scientific Research "Demokritos", 15310 Agia Paraskevi, Athens, Greece. E-mail: mariva@imel.demokritos.gr 